\title{
Narração e Experiência: olhares para uma educação "aquém" da pedagogia - um enfoque a partir de uma situação de aprendizado da escrita
}

\author{
Narration and experience: views for education \\ "beneath" the pedagogy - a study based on a learning \\ of writing situation
}

\author{
César Donizetti Pereira LEITE
}

\begin{abstract}
RESUMO
A partir de um enfoque que tem a sala de aula como referência central e tendo como ponto de partida uma situação concreta de sala de aula, este texto procura refletir uma perspectiva que possa sugerir uma prática docente que caminhe para uma pedagogia "aquém da pedagogia". Para isso trabalhará com uma noção de inversão de lógica no modo freqüente que pensamos a educação e que olhamos a escola. Nesta perspectiva, alguns eixos se tornam centrais, (1) o primeiro é produzir um olhar sobre a idéia de conhecimento e de aprender (2) o segundo de uma noção de uma certa noção do "ensinar" e finalmente o terceiro (3) a partir de um enfoque sobre a infância que cria uma necessidade de "infantilização" da pedagogia, ou seja, devemos caminhar para uma pedagogia que vá "aquém" da pedagogia. Trabalharei isto a partir de um estudo realizado com crianças em processo inicial de escolarização/alfabetização.
\end{abstract}

Palavras-chave: ensino, escola, infância, linguagem.

\begin{abstract}
From an approach that has the classroom as central reference and having as starting point a concrete situation of classroom this intends to reflect a perspective that can suggest one practical teacher that goes towards a pedagogy "beneath the pedagogy'. For this it will work with a notion of inversion of logic in the way that we frequently think about education and look at the school. In this perspective, some axles are central: (1) the first
\end{abstract}


one is to produce a view about the idea of knowledge and learning (2) the second one is a notion of a certain notion of 'to teach' and finally third (3) from an approach on infancy and to create a necessity of 'childishness' of the pedagogy, it means we must walk for a pedagogy that goes "beneath" the pedagogy. I will work this from a study carried through with children in initial process of education - literacy.

Index Terms: infancy, language, school, teaching.

\section{Introdução}

Aprender, conhecer, construir, saber. Ensinar, formar, informar, deformar, transmitir. Nos últimos anos muitos têm sido os modos de falar dos processos que ocorrem nas práticas educativas em nossa sociedade, em particular na escola. As discussões passam pelas reflexões metodológicas, pedagógicas, psicológicas e também pelas profundas transformações culturais e sociais que temos vivido. Contornam o sentimento de mal-estar que ecoam nos corredores das escolas e cola nas frustrações dos professores.

O que sabemos é que, marcados por profundos ir e vir, os debates sobre o que fazer na e pela educação pouco têm, efetivamente, contribuído para avanços. Não acredito que estes "fazeres" sejam apenas um amontoado de artigos, pesquisas e Políticas Públicas distantes e distanciados da realidade educacional. O que verifico é que, esta realidade, tem se constituído cada dia de forma mais complexa e multifacetada.

Este esfacelamento, este caco, tem solicitado/exigido do professor além do que muitas vezes ele se sente capaz (não digo aqui que ele não seja capaz, indico apenas que deste ponto de vista, a "incapacidade" é um sentimento presente na prática cotidiana do professor, que no "ter que fazer" acaba "confundindo" limitação, impotência com incapacidade). É comum ouvirmos dos professores que atividades além das que geralmente são atribuídas a ele se fazem presentes em seu cotidiano. Escuto dos professores, nas escolas, falas como "às vezes tenho que ser psicóloga de 
meus alunos, mãe, enfermeira, assistente social ..." ou ainda, "não sei o que fazer, cada dia a coisa esta mais difícil, ...”.

Este texto não tem a pretensão de resolver este problema, nem de indiciar caminhos para esta resolução. Procurarei refletir em uma perspectiva que possa sugerir outro olhar, outro enfoque, que aponte uma pedagogia “aquém da pedagogia”, para tanto a noção de uma certa inversão de lógica no modo freqüente que pensamos a educação e que olhamos a escola se faz necessário, nesta perspectiva alguns eixos se tornam centrais, (1) o primeiro é um olhar sobre a idéia de conhecimento e de aprender, (2) o segundo de uma certa noção do "ensinar" e finalmente o terceiro (3) a partir de um enfoque sobre a infância e de uma necessidade de "infantilização" da pedagogia, ou seja, devemos caminhar para uma pedagogia que vá "aquém" da pedagogia. Trabalharei isto a partir de um estudo realizado com crianças em processo inicial de escolarização/alfabetização, tomando como ponto de partida uma situação real de sala de aula.

\section{Experiência e Narração: pressuposto para pensar uma prática educativa}

$\mathrm{Na}$ reflexão que segue percorrerei um caminho que articule a noção de conhecimento e de aprender, o farei a partir das discussões de narrativa no pressuposto filosófico de Walter Benjamin. Partirei de uma situação real de sala de aula, em uma classe de $1^{\text {a }}$. Série do Ensino Fundamental, a cena descrita abaixo tem uma particularidade, pois mais do que fazer referência a um modelo de fracasso do escolar e da escola, demonstra uma noção de aprendizado que escapa a nossa freqüente idéia de sucesso escolar:

Em um momento de ditado em sala de aula, uma criança que chamarei de T. escreve, enquanto a professora dita:

— "Naná".

Ao ouvir, T. abre a cartilha, que estava embaixo da sua carteira, procura a lição da "Naná" e copia "Naná". Isso ocorre com várias palavras 
ditadas pela professora, por isso o aluno acerta todas, sempre encontrando as palavras nas respectivas lições. Porém, no final do ditado, a professora dita:

- Igreja.

Como era de se esperar, T. procura a lição da "Igreja" que não existia. Mas como Igreja era uma das palavras da lição da "Praça", T prontamente, copia "Praça". Após alguns minutos perguntamos para T. como ele faz com as palavras erradas e como as corrige. T. explica que quando a professora coloca na lousa ele as copia.

$\mathrm{O}$ que T. aprende? Como esta criança aprende em meio a tantas questões que nos parecem improváveis? O que, apesar de todas as impossibilidades postas na relação de ensino, proporciona este tal aprendizado da criança?

Procurando encontrar alguns indicativos neste processo, recorrerei ao pressuposto de Walter Benjamin, como já indicado, a partir de apontamentos tanto do referido autor como de Girgio Aganbem ${ }^{1}$. Farei um percurso a partir de suas idéias a respeito de experiência e da narração. Procurando compor algo que acene para as trilhas descontínuas destes autores e nelas encontrar questões que indiciem o problema da experiência e da narração e como estes pressupostos se relacionam com alguma idéia de conhecimento /aprendizagem.

Para começar indicarei que na corrente filosófica destes autores

[...] na atualidade, qualquer discurso sobre a experiência deve partir de uma constatação, a de que esta — a experiência — já não é algo realizável. Pois assim como foi privado de sua biografia, o homem contemporâneo está retirado de sua experiência. (AGAMBEN, 2004, p. 7)

Mas, o que significa isso? O que pode estar nos querendo dizer respectivamente os filósofos, alemão e italiano?

Para estes autores (BENJAMIN, 1996; AGAMBEN, 2004) a expropriação da experiência está no projeto que fundamenta a ciência

\footnotetext{
${ }^{1}$ Indicamos esta idéia pois são apontamentos mesmo que estaremos fazendo.
} 
moderna. Graças aos modelos de ciências e dos conceitos apresentados pela história do ocidente. Hoje entendemos que a experiência que se encontra espontaneamente se chama caso e se é expressamente buscada se chama experimento. A experiência comum não é mais um proceder de alguém que "tateia" no escuro, como se fosse uma vassoura giratória, “[...] como quem a noite caminhasse aqui e ali com a esperança de acertar um caminho justo, quando seria muito mais útil e prudente esperar o dia, acender uma luz e logo se dar com a rua." (AGAMBEN, 2004, p. 13). Agamben ainda continua:

A verdadeira ordem da experiência começa ao acender a luz, depois se vislumbrar o caminho, começando por uma experiência ordenada e madura, e não por aquela descontinua e enviesada, primeiro deduz os axiomas e logo depois se procede com novos experimentos. (AGAMBEN, 2004, p. 14).

As afirmações de Agamben nos levam a crer que na modernidade e, sobretudo nas e com as ciências modernas, vivemos em um universo da desconfiança e do não-entendimento da tal descontinuidade do tempo e das coisas, pois buscamos uma noção da exatidão e da linearidade que deve ser assegurada para que também nos sintamos seguros, pois é terrível quando nos perdemos em uma cidade, em suas ruas, pois nelas estamos seguros e assegurados por seus mapas e referências, o que importa é o sentimento de segurança e exatidão para que ele nos distancie dos labirintos, e caso nele entremos, devemos estar acompanhados senão de Ariadne, pelo menos do fio que ela nos apresenta para que dele consigamos sair, pois, muitas vezes, o difícil não é acabar com nossos monstros, mas é conseguir sair de nossos próprios labirintos.

Em certo sentido não precisaríamos nem ir até a Filosofia para observar estes fatos, a nossa realidade concreta de sala de aula nos mostra como que orientados pela Didática Magna de Comenius (1997) - séc. XVII e recortado por um discurso da disciplinarização e do controle, efetivamos uma forma que se pretende exata e dirigida, linear e precisa dos processos 
de ensino e aprendizagem, sugerindo algo que mais do que garantir "sucesso", conforta nossos medos e define nosso controle.

O problema parece se acentuar quando em nossa cultura precisamos estabilizar as coisas em alguma medida concreta e estável, e acabamos tendo que transformar a experiência em uma certificação científica na forma de experimento, pois ele permite deduzir as impressões sensíveis com a exatidão de determinações quantitativas e poder prever impressões futuras - responde a esta perda de certezas que, arranca, desloca a experiência para o mais fora possível do homem: os instrumentos e os números. Deste modo a experiência tradicional perde em realidade todo o valor.

Temos a partir destas discussões uma garantia que a modernidade nos ensinou a ter, de que se não seguirmos a risca e prescrições previstas no discurso científico da Psicologia e da Educação corremos o risco de produzir uma legião de pessoas com problemas e dificuldades, mas também corremos o risco de não saber o que falar sobre nossas vidas, que se tornam projetos de uma sucessão de cenas sem sentidos na qual nenhum enredo pode ser montado, onde por vezes nos tornamos sujeitos e em outras situações objetos.

Montaigne (1972), em seus Ensaios (talvez a última obra moderna sobre a experiência), define seu material como um tema sem forma, que não pode ingressar em uma produção elaborada na qual não é possível fundar nenhum juízo constante, pois “[...] não há nenhuma existência constante, nem em nosso ser nem nos objetos. De tal forma que não é possível estabelecer nenhuma certeza sobre um e outro."

Neste percurso, o que vemos é que a idéia de uma experiência separada do conhecimento exato e preciso, volta para nós tão estranha que temos esquecido que, até o nascimento da ciência moderna, ciência e experiência tinham cada uma o seu próprio lugar, e não é só isso, também era diferente o sujeito do qual dependiam. O sujeito da experiência era o sentido comum, presente em cada indivíduo, enquanto que o sujeito da 
ciência é a "inteligência", o intelecto agente que está separado da experiência - dito de outro modo, o conhecimento nem sequer tinha um sujeito no sentido moderno de um ego, senão que o indivíduo singular era o sub-jectum onde o intelecto agente, único e separado efetua o conhecimento. Para nós talvez fique mais fácil falar que o que se coloca é uma idéia de um sujeito da inteligência que se interage com um objeto do conhecimento.

Nesta separação entre experiência e ciência devemos ver o sentido das disputas em torno da unicidade e da separação e sua comunicação com o sujeito da experiência. Para o pensamento antigo, inteligência e alma não são em efeito a mesma coisa, e o intelecto não é, como estamos acostumados a pensar, uma faculdade da alma — de nenhum modo lhe pertence senão aquele separado, não mesclado, não passivo, senão a idéia que se comunicam para efetuar o conhecimento (Aristóteles). Assim, para a antiguidade o problema central do conhecimento não é a relação entre um sujeito e um objeto, senão a relação entre o uno e o múltiplo, de modo que o pensamento clássico desconhece o problema da experiência como tal, aquilo que para nós se apresenta como um problema da experiência em troca como um problema de relação, de participação ou ainda como prefere Platão de diferença, entre o intelecto separado e os indivíduos singulares, entre o uno e o múltiplo, entre o inteligível e o sensível, entre o humano e o divino.

Neste movimento um problema se apresenta, pois temos aprendido nos últimos anos que o processo de conhecer/aprender se dá ou se efetiva em uma perspectiva da relação de um sujeito e de um objeto; se assim o é, como poderíamos pensar se esta relação se apresentasse de outra forma, ou seja, se pudéssemos compreender que o aprender é um processo de atribuição de sentido que se dá através da experiência. Ou ainda, longe de ser algo que se produz, como propõem a modernidade, no intelecto, na cognição, que possa ser algo que se efetiva nas práticas cotidianas das relações humanas de atribuição de sentido às coisas e ao mundo. 
Vale lembrar que em alemão Benjamin descreve a palavra experiência como Erfahrung - usado no antigo alemão no sentido literal de percorrer, atravessar uma região durante uma viagem. Portanto, a verdadeira transmissão da experiência na fonte da narração tradicional, está na autoridade que não é devida a uma sabedoria particular, mas que circunscreve o mais pobre homem na hora de sua morte, ou seja, na única coisa que de fato nos une. Percorrer, atravessar, caminhar, andar significa literalmente deixar o conforto de casa e ir para o mundo, sendo que o mundo é o lugar das incertezas, das aberturas, das ex-posições. Assim, longe de ser algo certo, exato, garantido, aprender/conhecer é algo que abre para uma variedade de possibilidades em relação aos processos de atribuição de sentido, das coisas, do mundo.

Um dos problemas é que separado de nós mesmos e só podendo nos apropriar das experiências através dos objetos, nós já não a temos mais. Um exemplo que Benjamin usa para definir isso pode ser posto na idéia de fotografia, a experiência deixa de ser algo que carrego e passa a ser algo que está fora, e que eu tenho contato com algo exterior a mim e a minha própria sensação.

Ao procurar encontrar meios, formas de nos ligarmos ao outro, de nos efetivarmos como seres de experiência, e não como um sujeito que se relaciona a um objeto que aparece a temática da linguagem, pois esta passa então a ser o meio que me liga a experiência, me liga ao outro, mas também e ao mesmo tempo aquilo que me separa do outro, ou seja, a marca notória de minha separação, de meu distanciamento. E é pela linguagem também que atribuímos sentidos, não ao que é previamente dado, mas ao que na busca de tentar compor com o outro eu teço o fio que me liga e que por isso partilho, o fio que talvez T., da cena do início possa nos indicar, apresentar. 


\section{Educação e Escola: o problema do ensinar}

Definirei, grosso modo, educação como todo processo em que seres humanos se relacionam, e que neste relacionar-se se fazem se transformam. Desta forma, educação pressupõe um espaço de relações humanas onde palavras, sentidos, afetos, corpos, pessoas, se posicionam, marcam lugares, definem ações e se encontram. Neste sentido, nos educamos nas escolas, nas famílias, nas ruas, nos bares, nas Igrejas, no cotidiano. A educação em nossa cultura ocidental moderna acabou por se institucionalizar e ganhar os contornos dos muros das escolas e de nossas casas. Assim podemos ver a educação como uma possibilidade destas composições, como um (e)feito da experiência.

Porém, nossa "fome" de expropriação da experiência nos faz circunscrever esta produção de sentido em algo que possamos controlar, domar, e é aqui que recorro a Foucault que em A Ordem do Discurso é contundente, ao nos perguntar:

O que é, afinal, um sistema de ensino senão a ritualização da palavra, senão uma qualificação e uma fixação dos papéis dos sujeitos que falam, senão a constituição de um grupo doutrinário ao menos difuso, senão a distribuição e uma apropriação do discurso com seus poderes e seus saberes? (FOCAULT, 1999, p. 44-45).

Talvez por alguns termos utilizados, talvez pelo caráter contundente com que se manifesta, talvez pelo que de fato apresenta (a educação), Foucault acaba por marcar o caráter institucional, quase religioso da educação. É este aspecto que acaba por indicar, os muros, as cercas, os limites desta "prática" de ações entre os homens.

Ao nos trazer esta perspectiva, Foucault acaba marcando o lugar das ritualizações dos discursos que ao serem dogmatizados nos empurram às idéias de disciplina e de disciplinarização. Pensar etimologicamente estes termos poderia nos colocar diante de uma variedade de possibilidades, vou fazer apenas um destes movimentos. "Disciplina" segundo o glossário 
etimológico de termos usuais na prática docente de Castello e Márcico (1998) está certamente ligada ao verbo discere, que significa aprender. É daí também que se deriva palavra como discipulus — quem aprende - o aluno - o aprendiz - o discípulo. Em seus primeiros usos disciplina significa ensino, educação e posteriormente veio significar ensino, matéria ensinada. Estes dois significados acabaram se mantendo em português e ganhando os seguintes contornos: (1) disciplina enquanto poder — disciplina militar ou eu tenho problemas disciplinares com meus alunos. (2) e disciplina enquanto saber - disciplina de Matemática, Psicologia, Literatura, etc.

Falar de educação significa então falar de um campo de ações em que se relacionam "poder" e "saber". Falar de educação escolarizada significaria então falar em uma instituição em que este poder e este saber ganham estatuto, um lugar, como por exemplo, a escola. Nas palavras de Rancière

[...] a escola funciona, mais fortemente do que nunca, como analogia, como "explicação" da sociedade, isto é, como prova de que o exercício do poder é o exercício natural e único das desigualdades das inteligências. (RANCIÈRE, 2004, p. 200)

Vemos-nos diante de uma curiosa situação, a da relação de poder/saber que se estabelece na educação. A apropriação do saber garante ao sujeito o estatuto de poder sob o que não sabe. Relações que por vezes se orientam em práticas "emudecedoras", "infantilizadoras", práticas pedagógicas que marcam e definem modos e meio e um aprendizado reprodutivista de uma verdade supostamente única, de uma educação tutelar e não emancipatória.

A lógica da explicação comporta um princípio de regressão ao infinito, diz Rancière no seu livro $O$ Mestre Ignorante, e acrescenta que o problema é que o modo explicativo é sempre um modo de pensar, uma lógica do explicador, 
inteligência em duas. Há, segundo ele, uma inteligência inferior e uma inteligência superior. A primeira registra as percepções ao acaso, retém, interpreta e repete empiricamente, no estreito circulo dos hábitos e das necessidades. É a inteligência da criancinha e do homem do povo. A segunda conhece as coisas por suas razões, procede por métodos do simples ao complexo, da parte ao todo. É ela que permite ao mestre transmitir seus conhecimentos, adaptando-os as capacidades intelectuais dos alunos, e verificar se o aluno entendeu o que acabou de aprender. Tal é o principio da explicação... tal é o principio do embrutecimento. (RANCIÈRE, 2004, p. 22).

É importante observar que nesta lógica infere-se uma outra, a de que a relação entre duas inteligências se pauta pela concentração de um conhecimento nas mãos de uns, "os superiores", em detrimento da ignorância de outros, “os inferiores”. O "saber", garante ao superior o estatuto de poder sobre o inferior, neste saber guarda-se supostos segredos, tesouros, os quais somente mentes iluminadas poderão, na medida do possível e do indicado, revelar, trazer à luz, possibilitar o conhecimento.

É assim que se processa a educação, é assim que pais, professores e educadores protegem seus filhos, alunos, educandos; é assim que as práticas educativas são legitimadas por discursos científicos como os da Psicologia, Pedagogia, Filosofia, Sociologia e outros, ou seja, é inferiorizando que definimos o que supostamente é bom para o outro.

O que é perceptível neste quadro é que as inúmeras iniciativas, na busca de caminhos para a Educação, têm encontrado dificuldades em romper (se é que pretendem) com este modelo, e as práticas educativas continuam trombando em suas próprias pernas. Assim, procurar um caminho que produza um outro discurso se faz necessário, procurarei encontrar espaço para esta possibilidade e para isso recorrerei a uma discussão sobre a infância.

\section{Nos des-caminhos da infância}


Olhando para os mais diferentes modos de pensar a educação, dos modelos alternativos aos mais tradicionais, de concepções interacionistas e construtivistas aos modelos deterministas, todos acabam se aproximando, de algum modo, pelo menos em um aspecto, de que educar é em um certo sentido levar a criança da condição de ser este ser que ainda não é em um ser que um dia será. Vemos com isso alguns indicativos para ancoragem de nossa reflexão, pois se podemos compreender que "todo" projeto de transformar o in-fans - aquele que não possui a razão — em seres de razão, podemos compreender que as práticas educativas se organizam a partir das idéias de infância(s), mas que também, por analogia, buscam acabar com a infância do homem, ou seja, uma ritualização da educação estaria em se organizar para tirar a criança da infância e também a infância da criança, é assim que muitas vezes definimos práticas, ações, currículos, etc.

Neste percurso, toda a pedagogia se organiza a partir deste pressuposto e talvez por conta disso tenhamos muita dificuldade em entender o que $\mathrm{T}$. aprende e mesmo em admitir que aprendeu alguma coisa. Toda a pedagogia se organiza em torno de um discurso, que define, como já vimos, modos de conhecer e aprender, assim como modos de ensinar, meu intuito é pensar uma educação que não tenha a preocupação com esta pedagogização das práticas, mas que possa não acabar com a infância da criança, mas que possa permitir a volta de uma infantilização do adulto.

Neste sentido, uma educação que profane, transgrida a ritualização indicada, seria uma prática em que o predomínio da construção da razão não seria mais hegemônico e que a previsibilidade das ações docentes seriam pautadas também em um eterno vir-a-ser. Invertendo a lógica de Pietá, não seria o filho que deita no colo da mãe, mas o contrário, o adulto que deitaria no colo da criança e com ela aprenderia, a partir de outras possibilidades, fora do campo da razão. Como afirmou Picasso, numa frase que ficou célebre por sua contundência: “[...] aos doze anos, pintava como adulto... e precisei de toda a vida para pintar como uma criança." 
Assim, na cena descrita acima alguns ícones aparecem e ganham contornos interessantes, primeiro porque pensar a possibilidade de que há um aprendizado ali é indicar uma quase transgressão, ruptura com um prédefinido, com o que vem a ser conhecer, e segundo porque esta cena acaba sendo a porta de entrada de uma travessia que talvez tenhamos que fazer, pois se assumimos que há uma partilha de sentido ali $-\mathrm{T}$. sabe em que lições estão as palavras ditadas, sabe corrigi-las da lousa - ela pode ser o ponto de partida de vermos, não o erro, a impossibilidade, mas o caminho.

Para refletir um pouco mais sobre isso partirei da análise de dois filmes que retratam a questão da infância de modo interessante: $O$ Jardim Secreto de Agnieska Holland e Central do Brasil de Walter Salles $\mathrm{Jr}^{2}$.

O primeiro, apesar de ser um filme produzido na década de 80 e de retratar crianças possivelmente da primeira metade do século, possui alguns elementos interessantes para nossa apreciação. O filme trata da história de três crianças diferentes, de origens distintas, que se encontram devido a uma catástrofe ocorrida com uma delas, a protagonista do filme, de nome Mary Lennox. Mary é uma garota de dez anos de idade, natural da Índia e filha de pais ingleses. Logo no início da narrativa, após um terremoto, ela fica órfã e vai viver junto a seu tio em um castelo no interior da Inglaterra. A segunda criança é um garoto da mesma idade de Mary, seu primo que vive isolado e "adoecido" dentro de um quarto e que se chama Craven. A terceira criança é um garoto camponês que acompanhará Mary nas suas descobertas e transformações.

Os outros personagens da história são a governanta Medlock, dura com a vida, com os criados e com as crianças. Sua dureza é o que produz a

\footnotetext{
${ }^{2}$ Consideramos importante salientar que, apesar de admitirmos que há muitos filmes que refletem uma produtiva discussão em relação à infância e à criança, acabamos por escolhê-los afim de orientar nossas reflexões, sobretudo por que eles acabam dialogando com o "fio" que estamos tecendo neste trabalho, o fio que sugere uma inversão da lógica ocidental do predomínio da razão, para a lógica de que, muitas das possibilidades em torno da subjetividade e de sua constituição passam sim pela razão, mas desta como uma das possibilidades de constituição do sujeito. As explicações relativas estão nas discussões que se seguem no texto.
} 
doença de Craven e sustenta a tristeza da casa; uma criada de nome Martha, pessoa simples que dá toques de leveza ao peso da governanta, é quem rompe os valores culturais de Mary ensinado-a a brincar, a se vestir, a ser criança e, finalmente, o tio de Mary, Sr. Craven, um homem triste depois da morte da mulher.

No filme de Holland verificamos que alguns ícones são importantes. Dentre eles destacamos a chave e a menina. Tomaremos por base uma citação de Kramer (2000) para construirmos nossa argumentação, vejamos:

O filme começa com um terremoto e um incêndio, prenunciando tristeza e infelicidade: depois da morte da mãe e do pai, depois da perda da casa, a menina chega a um lugar onde não é nem esperada e nem querida. Mas com o desenrolar da história, o filme inverte clichês e reverte o fatalismo anunciado no início. O objeto central do enredo é a chave: a chave abre o jardim secreto que foi mantido trancado, como as crianças, portas e janelas são mantidas trancadas. Mas a chave que pode trancar pode também abrir. [...] Nele, são as crianças que escancaram as portas, as janelas, as frestas, os buracos. (KRAMER, 2000, p. 34)

É uma criança quem, na tentativa de sair do quarto trancado pela governanta, descobre a chave, e em um ato de desobediência, de fuga da regra determinada, abre o jardim e traz de volta a felicidade para o castelo.

Usaremos a chave como ícone da razão/não-razão, que tranca as possibilidades de encontrarmos caminhos e frestas para solução de problemas. Na criança vemos a possibilidade subversiva de romper com a lógica pré-definida.

Esta ruptura provocada pelas crianças, suas "artes", seu "cultivar" jardins, suas magias, medos, incertezas, inseguranças marcam uma ponte que as leva a romper com a dureza da governanta, uma dureza que se manifestava na opressão dos corpos, das roupas, das palavras e fundamentalmente da postura, que não atingia só a governanta, mas todos os moradores do castelo, pois, “[...] a intricada rede de constrições públicas e privadas acaba por aprisionar cada existência em suas malhas cada vez mais cerradas." (CALVINO, 1995, p. 19). 
Esta criança desordeira foge às regras e indica o lado "in-humano" do que consideramos o fundante do homem, e conseqüentemente a necessidade de ampliar a compreensão da infância na contemporaneidade, pois a razão e todo o seu processo de construção oculta aquilo que é essencial na infância, ou ainda no próprio homem. Deste modo, procuramos ver a criança como a possibilidade da reconstrução do lugar do sujeito na contemporaneidade. É a criança, a partir de sua não-razão, que pode ver o que o adulto oculta pela sua racionalidade e narra pelo seu discurso com uma pretensa palavra unívoca, de sentido pleno. É a criança, pelo imaginário, pelo seu faz-de-conta, que encontra, assim como Mary a encontrou no jardim, em meio à "pedras e galhos secos", a vida e as possibilidades de fazer florir o jardim que a princípio parecia morto.

Neste percurso de reflexão, vemos a sala de aula, a "suposta" dureza, como indicado a princípio na vida dos professores que, sem ajuda alguma, se ancoram em posturas que lhes dêem segurança, lhes dêem garantia de um lugar já narrado. Vemos os alunos, as crianças, que rompem com esta dureza ao romperem com a própria narração dela e para ela. Vemos também professores que nos olham pedindo ajuda. Talvez por conhecer a dureza da sala de aula, da vida das crianças, das suas próprias vidas, podem também saber o "peso" da leveza e seus caminhos possíveis para e na educação. Assim como a criança, com seus modos e formas de aprender tem muito a nos ensinar, o adulto/professor também tem, pois

[...] devemos recordar que essa idéia de um mundo constituído de átomos sem peso nos impressiona é porque temos experiência de peso das coisas; assim como não podemos admirar a leveza da linguagem se não soubermos admirar igualmente a linguagem dotada de peso (CALVINO, 1995, p. 27).

Assim como no Jardim Secreto, Central do Brasil também traz possibilidades para refletirmos sobre a questão da infância e de sua relação com a educação. Walter Salles retrata de modo interessante como é possível pensar a própria vida dentro deste complicado jogo entre o adulto e a 
criança. Em Central do Brasil as histórias de Dora, um adulto, e Josué, uma criança, personagens centrais do enredo, se confundem, e de modo diferentes ambos parecem buscar os mesmos objetivos, encontrar suas origens e a partir disso reconstruir suas próprias histórias. A busca de Dora se dá através da memória, em um reencontro simbólico com o pai, e de uma brusca mudança de sua vida. A de Josué está em encontrar na própria experiência o pai real, e assim a sua origem perdida. Segundo Gagnebin a

[...] totalização do objeto, independente de sua inserção cronológica. Enquanto origem, justamente, ela também testemunha a não realização da totalidade. Ela é ao mesmo tempo indício da totalidade e marca notória desta falta. (GAGNEBIN, 1994, p. 17)

Parece exatamente isto que Josué e Dora nos ensinam, a origem não designa somente a lei estrutural de constituição. Porém, seus caminhos são marcados por vários acontecimentos. Um deles, sobretudo, chama a nossa atenção por estar diretamente relacionado ao nosso tema.

Em várias passagens do filme vemos que, na tentativa de salvar Josué, Dora acaba sendo salva pelo menino. Isto fica explícito em uma cena em que as possibilidades, de equacionar sérios problemas que os dois enfrentavam, surgem na e da criança. Após um desmaio de Dora, ela acorda no colo de Josué. Aqui se inverte a lógica, é o adulto que deita no colo da criança, e não o inverso. Após esta cena, o que vemos, são os dois brincando. Brincadeira que é deixada por Josué, que sai a andar pela cidade e em poucos instantes encontra a solução dos problemas que enfrentavam. A criança pode olhar para alguns lugares, como os porões, de modo mais tranqüilo, sem sacrifício e com menos esforço que os adultos. Estes, para ver o que está oculto, velado, no porão, precisam se abaixar, se esforçar.

Esta temática assim posta nos faz pensar que na escola e nas relações que nela se efetivam, as possibilidades de reflexão em torno da constituição da subjetividade e das relações sociais indicam que em uma época como a nossa marcada por múltiplos olhares, e pelo desencantamento, a infância 
poderia mostrar à própria escola o seu lugar, como um lugar da possibilidade daquilo que é e não mais do que pode vir a ser.

Assim, o que parece desordem, caos, impossibilidade, poderia ser o verdadeiro rosto das coisas e as possibilidades poderiam estar no in-fans, ou ainda, segundo Benjamin, em outra passagem, a criança

Mal entra na vida e já é caçador. Caça os espíritos cujos vestígios fareja nas coisas; entre espíritos e coisas transcorre-lhes anos, durante o qual seu campo visual permanece livre de serem humanos. Sucede-lhe como em sonhos: ela não conhece nada estável; acontece-lhe de tudo, pensa a criança, tudo lhe sobrevém, tudo a acossa. Seus anos de nômade são horas passadas no bosque onírico. De lá ela arrasta a pressa para a casa, para limpá-la, consolidá-la, desenfeitiçála. Suas gavetas precisam transformar-se em arsenal zoológico, museu policial ou cripta (BENJAMIN, 1984, p. 79-80).

Assim, os "esconderijos", a "escrivaninha", o "labirinto" são imagens que Benjamin nos traz para dizer que, como Alice, da clássica obra de Lewis Carrol Alice no País das Maravilhas, a experiência ${ }^{3}$ e a formação ${ }^{4}$ "[...] revelam a estrutura misteriosa do desejo humano que não cessa com a obtenção da sua meta, mas se compraz em inventar e reinventar desvios, imagens, gestos e palavras..." (GAGNEBIN, 1994, p. 105).

O texto de Benjamin (1995) sobre a escrivaninha revela que a criança procura certa independência em relação ao ensino oficial, como se quisesse uma aprendizagem subversiva, clandestina, que fugisse ao dever e se materializasse no lúdico, uma clandestinidade que também aparece na cena de T. descrita acima. E nesse espaço, fora da racionalidade do discurso acadêmico, a criança encontra o seu modo de ser,

[...] ao passo que na escola o espírito lúdico foi substituído pelo dever. Com sua escrivaninha junto à janela a criança tem uma relação afetiva. Ela se tornou seu recanto favorito, um motivo de festa quando se reencontram ao voltar da escola (BOLLE, 1997, p. 10).

\footnotetext{
${ }^{3}$ No sentido benjaminiano, a experiência não se localiza em algo eminentemente pessoal, mas ultrapassa essa característica e abrange algo cultural.

${ }^{4}$ Novamente o termo é usado no sentido benjaminiano. Para ver mais sobre o assunto consulte nas Referências bibliográficas desse trabalho Bolle (1997).
} 
Dessa forma, vemos a possibilidade de subjetivação no espaço escolar, pois no contraponto da voz com maior peso do professor, a criança protagonista se vale da astúcia da mimese para desarmar o poder da instituição de ensino. Representando o espírito "lúdico", a escrivaninha, como simulacro da carteira escolar, consegue desmontar o austero poder desta (BOLLE, 1997, p. 10).

Refletindo sobre isso, é possível pensar que a imagem do homem colocada diante daquilo que está presente no prefixo in da palavra infância nos remete a nossa falta originária de linguagem, de palavra e de razão. Ora a infância coloca-nos ao pé a revelação esclarecida por Aganbem de uma experiência inefável:

[...] não por ter um início paradisíaco além das palavras, ao mesmo tempo sem palavras, sem linguagem e, porém, condição de possibilidade de sua eclosão - que essa experiência exclui que a linguagem possa se apresentar como totalidade da verdade. (apud GAGNEBIN, 1997, 182)

Isso nos deixaria fora da condição confortável em que nos encontramos como adultos, pois a razão possui também sua completude, e assim, a linguagem nos traz a marca da infância, como origem, como incompletude.

Dessa forma, a infância nos revela duas faces de nossa constituição enquanto sujeitos: uma na qual vivemos a ilusão da completude na vida adulta e a outra que escancara essa incompletude explícita na própria infância. Porque a infância não é “[...] humanidade completa e acabada, é porque a infância é, como diz Lyotard, in-humana que, talvez, ela nos indique o que há de mais verdadeiro no pensamento humano: a saber, sua incompletude.” (GAGNEBIN, 1997, p. 99). Assim, a criança revela a nós o que somos e o que tentamos a todo custo esconder: seres incompletos, inacabados, e é por isso também que se a pedagogização da educação produziu um discurso que nos leva a tirar a infância da criança e a criança 
da infância, talvez pensar uma educação que vá aquém da pedagogia possa fazer sentido e compor novas possibilidades.

\section{Referências bibliográficas}

AGAMBEN, Giorgio (2004). Infancia e Historia. Buenos Aires: Adriana Hidalgo Editora.

BENJAMIN, Walter (1984). Reflexões: a criança, o brinquedo, a educação. São Paulo: Summus.

BENJAMIN, Walter (1987). Obras escolhidas I: magia e técnica, arte e política. São Paulo: Brasiliense.

BENJAMIN, Walter (1995). Obras escolhidas II: rua de mão única. São Paulo: Brasiliense.

BOLLE, Willi (1997). A idéia de Formação na Modernidade. In: GUIRALDELLI JR., Paulo. (Org.). Infância, Escola e Modernidade. São Paulo: Cortez.

CALVINO, Ítalo (1995). Seis propostas para o próximo milênio. São Paulo: Companhia das Letras.

COMENIUS, Cornelius (1997). A didática magna. São Paulo: Martins Fontes.

CASTELLO, Angel; MARCICO, Claudia (1998). Glosario etimológico de términos usuales em la praxis docente. Buenos Aires. Mimeo.

FOUCAULT. Michel. (1999). A Ordem do Discurso. São Paulo: Loyola.

GAGNEBIN, Jeanne Marie (1994). História e narração em W. Benjamin. São Paulo: Ed. Perspectiva.

GAGNEBIN, Jeanne Marie (1997). Infância e pensamento. In: GUIRALDELLI JR., Paulo. (Org.). Infância, Escola e Modernidade. São Paulo: Cortez.

KRAMER, Sônia (2000). Infância e Educação Infantil: Reflexões e Lições. LEITE, C. D. P. Educação, Psicologia e Contemporaneidade. Taubaté: Cabral Editora Universitária.

MONTAIGNE, Michel de (1972). Ensaios. Tradução Sérgio Milliet. São Paulo: Editor Victor Civita. 
RANCIÈRE, Jacques (2004). O Mestre Ignorante. 2. ed. Belo Horizonte: Autêntica.

\author{
Autor \\ César Donizetti Pereira Leite \\ Doutor em Educação - Faculdade de Educação - UNICAMP. Prof. Doutor \\ do Departamento de Educação - UNESP - Rio Claro. \\ Fone: Sec. (19) 3526-4245. Sala: (19) 3526-4271 \\ Endereço Profissional: Av. 24 A, 1515 - Bairro Bela Vista - Rio Claro - SP \\ - 13506-900 \\ $\underline{\text { mvhleite@uol.com.br e cesar@rc.unesp.br }}$
}

\title{
Como citar este artigo:
}

LEITE, César Donizetti Pereira. Narração e Experiência: olhares para uma educação "aquém" da pedagogia - um enfoque a partir de uma situação de aprendizado da escrita. Revista ACOALFAplp: Acolhendo a Alfabetização nos Países de Língua portuguesa, São Paulo, ano 2, n. 3, 2007. Disponível em: <http://www.mocambras.org> e ou <http://www.acoalfaplp.org>. Publicado em: setembro 2007. 